\title{
Early Treatment with Methylprednisolone Pulse Therapy Combined with Tonsillectomy for Heavy Proteinuric Henoch-Schönlein Purpura Nephritis in Children
}

\author{
Hiroaki Kanai Emi Sawanobori Anna Kobayashi \\ Kyoko Matsushita Kanji Sugita Kosuke Higashida \\ Department of Pediatrics, Faculty of Medicine, University of Yamanashi, Chuo-city, Japan
}

\section{Key Words}

Henoch-Schönlein purpura nephritis $\cdot \lg A \cdot$ Methylprednisolone pulse therapy $\cdot$ Proteinuria Tonsillectomy

\begin{abstract}
Background: There is no clear consensus as to which patients with Henoch-Schönlein purpura nephritis (HSPN) at risk of a poor outcome should be treated and what therapeutic regimen should be used. Methods: Nine children with heavy proteinuric HSPN received prompt initiation of methylprednisolone pulse therapy (MPT) combined with tonsillectomy in a prospective study. Results: At presentation, the mean values for the patients' urine protein excretion (earlymorning urinary protein/creatinine ratio), serum IgA, activity index (Al), and chronicity index (Cl) were $5.0 \pm 5.6 \mathrm{~g} / \mathrm{g} \mathrm{Cr}, 135.6 \pm 56.5 \mathrm{mg} / \mathrm{dl}, 4.0 \pm 0.7$, and $1.7 \pm 1.3$, respectively. At the second biopsy, conducted approximately 24 months after initiation of therapy, the patients' serum albumin had significantly increased $(4.4 \pm 0.2, \mathrm{p}<0.01)$, and the serum $\lg \mathrm{A}$ and Al had significantly decreased $(88.1 \pm 30.8 \mathrm{mg} / \mathrm{dl}, \mathrm{p}<0.05 ; 2.0 \pm 1.2, \mathrm{p}<0.01$, respectively), whereas the $\mathrm{Cl}$ remained unchanged. Proteinuria disappeared within 24 months in all but 1 patient, and hematuria disappeared within 38 months in all patients. No patient showed renal impairment or experienced a recurrence and/or exacerbation of HSP/HSPN. Conclusions: Early treatment with MPT combined with tonsillectomy is effective in ameliorating the histopathological progression and improving the clinical course of children with heavy proteinuric HSPN.
\end{abstract}

Copyright $\odot 2011$ S. Karger AG, Basel 


\section{Introduction}

Henoch-Schönlein purpura (HSP) is an IgA-mediated immune-complex vasculitis that predominantly affects the skin, joints, gastrointestinal tract, and kidneys. HSP nephritis (HSPN) is associated with HSP and usually occurs within 1-2 months of the onset of HSP. HSPN is estimated to occur in 20-60\% of HSP cases, typically in young children. Most children with HSPN present only with hematuria and/or low-grade proteinuria and have good prospects for recovery. Renal involvement is the major cause of morbidity and mortality in patients with HSP. Although the prognosis for most pediatric HSPN is favorable, patients with $>50 \%$ crescents, nephrotic syndrome, heavy proteinuria, hypertension, or renal insufficiency at onset have been reported to be at risk of a poor outcome [1-7]. However, because of the small number of patients with severe HSPN and the variable severity of HSPN, there is no clear consensus as to which patients with HSPN should be treated and what therapeutic regimen should be used.

It has been suggested that HSPN and IgA nephropathy represent a spectrum of clinical presentations of similar disorders. Although the pathogenesis of HSP and HSPN is not known, increased polymeric IgA (IgA1) production by the mucosal immune system, including the tonsils, in response to certain antigens has been hypothesized as a potential mechanism for the development of the disease. Histopathologically, the granular IgA and C3 immune deposits found predominantly in the mesangium are indistinguishable from those seen in IgA nephropathy. It has long been speculated that HSPN and IgA nephropathy share common pathogenic mechanisms and may represent different ends of a continuous spectrum of disease [8-11].

Severe HSPN and IgA nephropathy in children have been treated with steroids as an adjunct to immunosuppressant therapy. Recently, some studies have reported the efficacy of tonsillectomy plus methylprednisolone pulse therapy (MPT) in adults and children with IgA nephropathy [12-14]. However, there are few reports on the efficacy of tonsillectomy combined with MPT for HSPN [15-17]. Furthermore, there has been no prospective study of tonsillectomy plus MPT in pediatric HSPN. Therefore, to evaluate the efficacy of MPT combined with tonsillectomy for HSPN, which has a similar pathogenesis to IgA nephropathy, we selected a similar therapeutic regimen for HSPN in children.

In the present study, we prospectively analyzed the clinical and histopathological outcomes of heavy proteinuric HSPN in children who underwent early treatment with MPT combined with tonsillectomy as the initial treatment.

\section{Patients and Methods}

\section{Patients}

Between March 2003 and September 2005, we recruited 10 patients who were newly diagnosed with HSPN with persistent heavy proteinuria ( $>1$ month) and hematuria. Of the 10 patients, 9 patients and/or their parents provided written informed consent to participate in our therapeutic regimen and to undergo renal biopsy before and after treatment at the Department of Pediatrics at the Yamanashi University of Medicine. The study protocol was in accordance with the standards followed at our center. HSPN was diagnosed when hematuria/ proteinuria was associated with a characteristic purpuric rash and abdominal/joint pain. Among the 9 patients, HSPN occurred during the first episode of HSP in 8 patients and during the first relapse of HSP in 1 patient. None of the patients had a history of recurrent or habitual tonsillitis. All patients were treated - regardless of the severity of the patients' histopathological findings - and treatment started within 1 month of the first renal biopsy. 


\section{Definitions}

Hematuria was considered a positive finding if urinary microscopic examination showed $\geq 5$ red blood cells per high-power field. Proteinuria was evaluated by an early-morning urinary total protein/creatinine ratio (u-TP/Cr). In many studies, heavy proteinuria is defined as a urinary protein excretion of $\geq 40 \mathrm{mg} \cdot \mathrm{m}^{-2} \cdot \mathrm{h}^{-1}$. Because it has been reported that $\mathrm{u}-\mathrm{TP} / \mathrm{Cr}$ $\geq 1 \mathrm{~g} / \mathrm{g}$ Cr is equivalent to $\geq 40 \mathrm{mg} \cdot \mathrm{m}^{-2} \cdot \mathrm{h}^{-1}$, we defined heavy proteinuria as $\mathrm{u}-\mathrm{TP} / \mathrm{Cr} \geq 1 \mathrm{~g} / \mathrm{g}$ $\mathrm{Cr}$ in the present study [18]. The disappearance of proteinuria was defined as $\mathrm{u}-\mathrm{TP} / \mathrm{Cr}<0.2$ $\mathrm{g} / \mathrm{g} \mathrm{Cr}$ [19]. Nephrotic syndrome was defined as the presence of heavy proteinuria with hypoalbuminemia (serum albumin $<2.5 \mathrm{~g} / \mathrm{dl}$ ). Hypertension was defined as a systolic or diastolic blood pressure $>95$ th percentile for the patient's age, based on the recommendations of the Pediatric Task Force [20].

HSPN patients were classified into 5 grades according to the initial clinical presentation. A modified Meadow's classification was used as follows: grade 1, microscopic hematuria; grade 2, persistent proteinuria and/or hematuria; grade 3, nephritic syndrome (hematuria, decrease in glomerular filtration rate, GFR, oliguria, hypertension, and edema); grade 4 , nephrotic syndrome (u-TP/Cr $<1 \mathrm{~g} / \mathrm{g} \mathrm{Cr}$, hypoalbuminemia with serum albumin $<2.5 \mathrm{~g} / \mathrm{dl}$ and/or hyperlipidemia/edema), and grade 5 , mixed nephritic-nephrotic syndrome $[21,22]$.

The clinical outcome was also graded according to the modified Meadow's criteria for each patient at the second biopsy and the most recent follow-up: state A, normal: physical examination, urine, and renal function normal; state B, minor urinary abnormalities: normal physical examination with microscopic \pm recurrent macroscopic hematuria and/or proteinuria (u-TP/Cr $<1.0 \mathrm{~g} / \mathrm{g} \mathrm{Cr}$ ); state $\mathrm{C}$, active renal disease: proteinuria (u-TP/Cr $\geq 1.0 \mathrm{~g} / \mathrm{g}$ $\mathrm{Cr}) \pm$ hypertension, and estimated GFR (eGFR) $>60 \mathrm{ml} / \mathrm{min} / 1.73 \mathrm{~m}^{2}$ according to the Schwartz formula [23]; state $\mathrm{D}$, renal insufficiency: eGFR $<60 \mathrm{ml} / \mathrm{min} / 1.73 \mathrm{~m}^{2}$ (including dialysis/transplant or death) [21].

\section{Pathology}

All patients underwent percutaneous renal biopsy before treatment. The interval between the onset of HSPN and the renal biopsy was $2.7 \pm 3.9$ months (range, $0.5-13$ months). To evaluate the treatment, a second renal biopsy was performed on each patient after completion of therapy. Glomerular changes were graded according to the classification of the International Study of Kidney Diseases in Childhood (ISKDC), using the scoring system for IgA nephropathy described by Andreoli and Bergstein [24]. The activity index (AI) was determined by grading mesangial cell proliferation on a scale of $0-3(0=$ none, $1=$ mild, $2=$ moderate, and $3=$ severe), interstitial mononuclear cell infiltration on a scale of $0-3$, and cellular crescent formation on a scale of $0-3$ according to the percentage of glomeruli involved $(0=0 \%, 1=1-20 \%, 2=21-50 \%$, and $3=>50 \%)$. The sum of these numbers was the AI (maximum =9). The chronicity index $(\mathrm{CI})$ was obtained by determining the number of glomeruli demonstrating fibrous crescents and the presence of segmental or global sclerosis; each of these factors was scored on a scale of $0-3$ according to the percentage of glomeruli involved $(0=0 \%, 1=1-20 \%, 2=21-50 \%$, and $3=>50 \%)$. Tubular atrophy and interstitial fibrosis were also each scored on a scale of $0-3$. The sum of these numbers was the CI (maximum = 12). Tubulointerstitial $(\mathrm{TI})$ changes were classified according to TI scores described by Foster et al. [25]. In brief, the interstitial mononuclear cell infiltration, interstitial edema, tubular damage, and interstitial fibrosis/tubular atrophy were each scored on a scale of $0-2$ on the basis of the percentage of TI lesions involved (absent $=0 \%$, $1=1-50 \%$, and $2=>50 \%$ ). The second renal biopsies were performed after completion of therapy. 


\section{Treatment Protocol}

The treatment regimen consisted of MPT $\left(30 \mathrm{mg} \cdot \mathrm{kg}^{-1} \cdot \mathrm{day}^{-1}\right.$ i.v., maximum 1,000 mg/ day) for 3 consecutive days each week for 3 weeks, followed by combination therapy of alternate-day oral prednisolone (initially $2 \mathrm{mg} / \mathrm{kg}$, maximum $60 \mathrm{mg}$ ) and antiplatelet agents (dipyridamole or dilazep hydrochloride $3-5 \mathrm{mg} \cdot \mathrm{kg}^{-1} \cdot \mathrm{day}^{-1}$ ) for 24 months. After 3 months, the dosage of alternate-day oral prednisolone was decreased by $1 \mathrm{mg} / \mathrm{kg}$ (maximum, $40 \mathrm{mg}$ ) and gradually tapered off according to the proteinuria grade. Tonsillectomy was performed between cycles of MPT during oral prednisolone $\left(2 \mathrm{mg} \cdot \mathrm{kg}^{-1} \cdot \mathrm{day}^{-1}\right)$ therapy. In addition, 2 patients (Nos. 7 and 8) whose initial renal biopsy had shown $\geq 50 \%$ crescentic glomeruli (ISKDC classification: grade IV) also received intravenous cyclophosphamide therapy (500$1,000 \mathrm{mg} / \mathrm{m}^{2}$ once a month; total of $\left.6,000 \mathrm{mg} / \mathrm{m}^{2}\right)$ followed by azathioprine $(2-2.5 \mathrm{mg}$. $\mathrm{kg}^{-1} \cdot \mathrm{day}^{-1}$ ) after MPT and tonsillectomy.

\section{Statistics}

The data are expressed as means $\pm \mathrm{SD}$. They were analyzed using a paired t test with StatMate for Windows (GraphPad Software, La Jolla, Calif., USA). The disappearance rates of proteinuria and hematuria were analyzed using the Kaplan-Meier method. A value of $\mathrm{p}<0.05$ was considered significant.

\section{Results}

The clinical characteristics of the 9 patients at the first renal biopsy are shown in table 1 . The patient population consisted of 3 boys and 6 girls, with a median age at HSP onset of $7.2 \pm 2.3$ years (range, 4.2-11.3 years). The interval from the onset of HSP to HSPN was $3.0 \pm 6.0$ months (range, $0.2-19$ months). The mean period between the onset of HSPN and initiation of therapy was $3.0 \pm 3.8$ months (range, $0.7-13$ months). The mean interval from the first biopsy to the second biopsy was $20.8 \pm 5.5$ months. All of the patients had heavy proteinuria with hematuria (patient 5 had macrohematuria). One patient (No. 7) had nephrotic syndrome. No patients had renal insufficiency (eGFR $<60 \mathrm{ml} / \mathrm{min} / 1.73 \mathrm{~m}^{2}$ ) or hypertension. The mean u-TP/Cr, serum albumin, serum IgA, and eGFR were $5.0 \pm 5.6 \mathrm{~g} / \mathrm{g} \mathrm{Cr}$, $3.3 \pm 0.6 \mathrm{~g} / \mathrm{dl}, 154.7 \pm 77.8 \mathrm{mg} / \mathrm{dl}$, and $110.4 \pm 12.4 \mathrm{ml} / \mathrm{min} / 1.73 \mathrm{~m}^{2}$, respectively. Clinical status was grade 2 for 8 patients and grade 4 for 1 patient. The grades of glomerular changes according to the ISKDC classification at the initial biopsy were grade IIb for 1 patient, grade IIIa for 3 patients, grade IIIb for 3 patients, and grade IVb for 2 patients. The mean AI, CI, and TI scores were $4.0 \pm 0.7,1.7 \pm 1.3$, and $1.3 \pm 0.7$, respectively. All patients completed the study. All of the patients' tonsils showed chronic tonsillitis on histological results.

At the second renal biopsy, 6 patients had normal urinalysis and renal function (state A), 2 patients (Nos. 2 and 6) had minor urinary abnormalities (state B), and 1 patient (No. 8) had active renal disease (state C). Serum albumin had significantly increased $(4.3 \pm 0.2 \mathrm{~g} / \mathrm{dl}$, $\mathrm{p}<0.01)$, and the serum IgA, AI , and TI scores had significantly decreased $(88.1 \pm 30.8 \mathrm{mg} /$ $\mathrm{dl}, \mathrm{p}<0.05 ; 2.0 \pm 1.2, \mathrm{p}<0.01$, and $0.4 \pm 0.5, \mathrm{p}<0.01$, respectively). CI and eGFR values did not change compared with those at the first renal biopsy (table 2). All of the patients but 1 (No. 6) had an improved ISKDC grade. Two patients (Nos. 6 and 8) received additional therapy because they exhibited persistent proteinuria and hematuria at the second renal biopsy, although proteinuria and hematuria largely decreased. Patient No. 6 had mild proteinuria ( $\mathrm{u}-\mathrm{TP} / \mathrm{Cr}$ of approximately $>0.3-0.4 \mathrm{~g} / \mathrm{g} \mathrm{Cr}$ ) and hematuria that persisted at the second renal biopsy, so the patient received 2 cycles of MPT followed by azathioprine and an angiotensin-converting enzyme inhibitor (ACEI; enalapril). Patient 8 received azathioprine combined with alternate-day oral prednisolone; however, heavy proteinuria (u-TP/Cr of approx- 
Table 1. Histopathological and laboratory data of all patients

\begin{tabular}{|c|c|c|c|c|c|c|c|c|c|c|c|}
\hline $\begin{array}{l}\mathrm{Pa}- \\
\text { tient } \\
\text { No. }\end{array}$ & Sex & $\begin{array}{l}\text { Age at } \\
\text { biopsy } \\
\text { years }\end{array}$ & $\begin{array}{l}\mathrm{u}-\mathrm{TP} / \mathrm{Cr} \\
\mathrm{g} / \mathrm{g} \mathrm{Cr}\end{array}$ & $\begin{array}{l}\text { Interval } \\
\text { between } \\
\text { biopsies } \\
\text { months }\end{array}$ & AI & CI & TI & $\begin{array}{l}\text { ISKDC } \\
\text { grade }\end{array}$ & $\begin{array}{l}\text { Albu- } \\
\mathrm{min} \\
\mathrm{g} / \mathrm{dl}\end{array}$ & $\begin{array}{l}\text { eGFR } \\
\mathrm{ml} / \mathrm{min} / \\
1.73 \mathrm{~m}^{2}\end{array}$ & $\begin{array}{l}\text { Follow-up } \\
\text { months }\end{array}$ \\
\hline \multirow[t]{2}{*}{1} & $\mathrm{~F}$ & 9.2 & 6.4 & 24 & 4 & 2 & 1 & IIIb & 2.6 & 104.5 & 53 \\
\hline & & & & & 1 & 0 & 1 & I & 4.6 & 103.7 & \\
\hline \multirow[t]{2}{*}{2} & $\mathrm{M}$ & 6.8 & 1.1 & 24 & 4 & 1 & 1 & IIIa & 3.7 & 122.6 & 51 \\
\hline & & & & & 2 & 2 & 1 & IIIa & 4.2 & 121.7 & \\
\hline \multirow[t]{2}{*}{3} & $\mathrm{~F}$ & 9.7 & 1.9 & 25 & 4 & 1 & 2 & IIIb & 4.0 & 128.6 & 46 \\
\hline & & & & & 2 & 1 & 1 & IIIa & 4.4 & 117.9 & \\
\hline \multirow[t]{2}{*}{4} & $\mathrm{~F}$ & 5.8 & 1.5 & 10 & 3 & 0 & 1 & IIIa & 3.8 & 98.7 & 49 \\
\hline & & & & & 1 & 1 & 1 & IIIa & 4.3 & 111.5 & \\
\hline \multirow[t]{2}{*}{5} & $\mathrm{~F}$ & 7.3 & 5.3 & 23.5 & 4 & 2 & 1 & IIIb & 3.0 & 122.6 & 49 \\
\hline & & & & & 2 & 1 & 0 & IIIa & 4.1 & 103.6 & \\
\hline \multirow[t]{2}{*}{6} & $\mathrm{~F}$ & 11.4 & 4.2 & 21 & 4 & 3 & 1 & IIIa & 3.3 & 113.6 & 35 \\
\hline & & & & & 4 & 4 & 0 & IIIb & 4.0 & 120.8 & \\
\hline \multirow[t]{2}{*}{7} & M & 6.3 & 19.2 & 22 & 5 & 2 & 1 & IVb & 2.3 & 110.9 & 44 \\
\hline & & & & & 1 & 2 & 0 & IIIa & 4.4 & 112.0 & \\
\hline \multirow[t]{2}{*}{8} & M & 5.3 & 3.2 & 13 & 5 & 4 & 3 & IVb & 3.3 & 95.8 & 31 \\
\hline & & & & & 4 & 2 & 0 & IIIa & 4.1 & 112.4 & \\
\hline \multirow[t]{2}{*}{9} & $\mathrm{~F}$ & 7.4 & 2.4 & 24.5 & 3 & 0 & 1 & IIb & 3.5 & 96.0 & 34 \\
\hline & & & & & 1 & 0 & 0 & IIa & 4.4 & 81.2 & \\
\hline
\end{tabular}

Table 2. Comparison between the laboratory and histopathological data

\begin{tabular}{lccc}
\hline Variable & First renal biopsy & Second renal biopsy & Latest follow-up \\
\hline Serum albumin, g/dl & $3.3 \pm 0.6$ & $4.3 \pm 0.2^{\mathrm{a}}$ & $4.4 \pm 0.2^{\mathrm{a}}$ \\
eGFR, $\mathrm{ml} / \mathrm{min} / 1.73 \mathrm{~m}^{2}$ & $110.4 \pm 12.4$ & $109.4 \pm 12.4^{\mathrm{NS}}$ & $116.0 \pm 13.0^{\mathrm{NS}}$ \\
Serum IgA, mg/dl & $135.6 \pm 56.5$ & $88.1 \pm 30.8^{\mathrm{b}}$ & $98.8 \pm 47.0^{\mathrm{b}}$ \\
AI & $4.0 \pm 0.7$ & $2.0 \pm 1.2^{\mathrm{a}}$ & \\
CI & $1.7 \pm 1.3$ & $1.4 \pm 1.2^{\mathrm{NS}}$ & \\
TI scores & $1.3 \pm 0.7$ & $0.4 \pm 0.5^{\mathrm{a}}$ & \\
\hline
\end{tabular}

${ }^{\mathrm{a}} \mathrm{p}<0.01,{ }^{\mathrm{b}} \mathrm{p}<0.05$, vs. first renal biopsy. NS $=$ Nonsignificant. Data are expressed as means $\pm \mathrm{SD}$.

imately $>1-2 \mathrm{~g} / \mathrm{g} \mathrm{Cr}$ ) and hematuria persisted at the second renal biopsy. Therefore, he received 3 cycles of MPT followed by mizoribine $\left(5 \mathrm{mg} \cdot \mathrm{kg}^{-1} \cdot \mathrm{day}^{-1}\right)$ and an ACEI (enalapril). Two patients received an ACEI to decrease proteinuria and for renal protection, but not for hypertension.

The median follow-up lasted $43.6 \pm 8.2$ months (range, 31.0-53.0 months). At the most recent follow-up, 8 patients were in state A and only 1 (No. 8) was in state B. Two patients (Nos. 6 and 8 ) had received an ACEI at this point in time. All of the patients had negative hematuria within 38 months, and the mean time for hematuria disappearance was $16.1 \pm$ 13.1 months (range, 1-38 months). All but 1 patient (No. 8) had negative proteinuria within 
Fig. 1. The times for disappearance of proteinuria (u-TP/Cr $<0.2 \mathrm{~g} / \mathrm{g} \mathrm{Cr}$ ) and hematuria are shown.

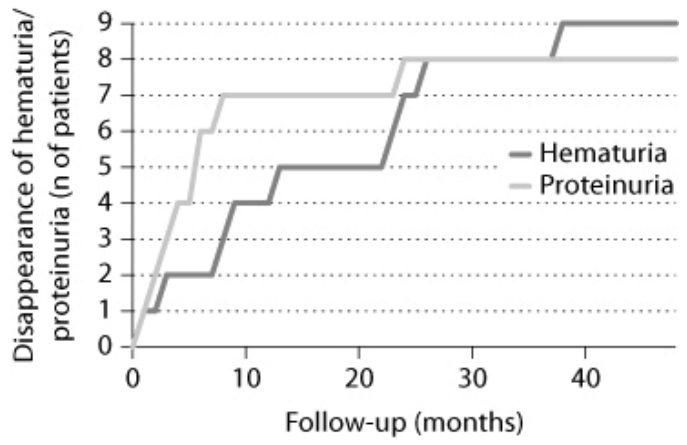

24 months, and the mean time for proteinuria disappearance was $6.7 \pm 7.4$ months (range, 2-24 months; fig. 1). In 7 patients (Nos. 1-5, 7 and 9), proteinuria promptly disappeared within 8 months. These patients did not require additional therapy, and there was no association between their first histopathological findings (ISKDC classification and the AI) and urine protein quantity. Patient 7 had persistent low-grade proteinuria and hematuria at the second biopsy (21 months after the start of therapy). However, after the additional therapy, proteinuria promptly disappeared 2 months later. Patient 8 had persistent proteinuria with a u-TP/Cr of approximately $0.5-0.7 \mathrm{~g} / \mathrm{g} \mathrm{Cr}$ without hematuria (clinical status, state B) despite additional aggressive immunosuppressive treatment. Hematuria disappeared in all patients, but no association was found between the duration of disappearance and any other parameter. Furthermore, no decrease in renal function (eGFR in all patients was $>80 \mathrm{ml} /$ $\left.\mathrm{min} / 1.73 \mathrm{~m}^{2}\right)$ was noted, and persistent low levels of serum IgA $(98.8 \pm 47.0 \mathrm{mg} / \mathrm{dl})$ were noted. None of the patients progressed to state $\mathrm{D}$ during the course of the study, and none experienced recurrence and/or exacerbation of HSPN or a relapse of HSP after treatment initiation.

No serious complications were reported during the course of therapy, and all complications were reversible. No patients developed glaucoma, cataract, diabetes, or hypertension. No major or minor infections were observed. Four patients had body weight gain $>10 \%$ of the standard weight for their age at the time of the second renal biopsy. The growth rate did not change significantly during the prednisolone therapy, and no patients showed a stature of $<-2.0 \mathrm{SD}$ for their age. Dual-energy X-ray absorption results were not significantly different before and after the treatment. No patients required a change in the therapy regimen due to side effects.

\section{Discussion}

Although previous reports have indicated that the prognosis for most pediatric HSPN is favorable, patients with $>50 \%$ crescents, nephrotic syndrome, hypertension, or renal insufficiency at onset have been reported to be at risk of a poor outcome [1-6]. In addition, morbidity among HSPN patients with persistent heavy proteinuria is high, and the decision to treat HSPN should be based on clinical presentation rather than on biopsy findings alone [7]. The limitations associated with predicting the future prognosis according to clinical features or histological evaluation at early-stage HSPN may provide us with a rationale for treating 
all proteinuric HSPN children [26]. In addition, it was recently reported that patients with ISKDC grade I-III and serum albumin $>2.5 \mathrm{~g} / \mathrm{dl}$ might have recovered with ACEI and/or angiotensin receptor blockers [27].

From the results of such reports, we concluded that, with no definite criteria about the treatment decisions in HSPN patients, the treatment must be judged on the basis of the clinical features, histopathology, and laboratory findings. In the present study, all but 2 of our HSPN patients had serum albumin $>2.5 \mathrm{~g} / \mathrm{dl}$ and/or ISKDC grade II or III. It is controversial whether such HSPN patients need aggressive therapy. In general, however, early treatment is necessary for severe HSPN patients, and it is widely recognized that HSPN patients with heavy proteinuria and/or $>50 \%$ crescents pathologically have a poor renal prognosis. We selected HSPN patients with heavy proteinuria for treatment adaptation and then determined the treatment intensity (intravenous cyclophosphamide therapy followed by azathioprine) by the severity of pathology. Thus, we decided that all patients in the present study would receive the aggressive treatment.

Several previous studies have reported improvement in renal symptoms in pediatric HSPN patients treated with immunosuppressive agents, including MPT alone [28], MPT and urokinase pulse therapy [29], oral cyclophosphamide [30], corticosteroids in combination with cyclophosphamide [31,32], cyclosporin A [33], azathioprine with steroids [34], and plasmapheresis [35]. However, the severity of the cases in these studies differed, and there is no clear consensus as to which patients with HSPN should be treated or what therapeutic regimen should be used. No treatment regimen has been evaluated in randomized, controlled trials because of the small number of HSPN patients and the variable severity of HSPN.

Recently, case reports were published on the efficacy of tonsillectomy for HSPN in adults and children $[15,17]$. Persistent proteinuria and chronic progressive renal dysfunction should be considered therapeutic targets in HSPN, and tonsillectomy combined with subsequent pulse steroids may be a therapeutic strategy deserving consideration for patients with those conditions. Furthermore, the efficacy of tonsillectomy plus MPT was reported for severe pediatric HSPN in a retrospective study. It was concluded that tonsillectomy in combination with steroid therapy was able to induce complete remission of various grades of HSPN; tonsillectomy in early-stage HSPN significantly reduced the time until the urine findings returned to normal, and tonsillectomy appeared to contribute to the prevention of HSPN relapses [16]. The $100 \%$ success rate of that study in achieving complete remission with HSPN therapy could be attributed to prompt intervention against disease activity by steroid administration, including MPT. Inoue et al. [36] also reported that tonsillectomy alone might be able to prevent complications of HSPN, thereby contributing to early recovery from HSP in children.

In blood, subtype IgA 1 accounts for $90 \%$ of IgA, and approximately $80-90 \%$ of $\operatorname{IgA} 1$ is produced in the tonsils and nasal cavity. In the mechanism of action for HSPN treatment with MPT combined with tonsillectomy, production of the IgA1 antibody in the tonsils is inhibited because the focal infection is removed by tonsillectomy, as in IgA nephropathy, and inferred inflammation in the glomerulus, especially the glomerular capillary, is treated with MPT followed by oral prednisolone therapy. A recent report suggested the rationale for the superiority of tonsillectomy plus MPT over MPT alone for the treatment of IgA nephropathy: tonsillectomy may have effects upstream of the pathogenic mechanism by eliminating antigenic stimuli from the tonsillar mucosa, and MPT can influence the area downstream of the pathogenic mechanism by suppressing the abnormal immune response in the bone marrow that leads to subsequent inflammation in the renal glomeruli [37]. A similar mechanism is possible for the effect of MPT plus tonsillectomy on HSPN. Our study showed that the serum IgA level decreased significantly after tonsillectomy, a low level of serum IgA persisted for an extended period, and proteinuria promptly disappeared in all but 1 patient. These find- 
ings suggest that a reduction in polymeric IgA1 production did not lead to the development of inflammation in the glomeruli and eliminated antigenic stimuli from the tonsillar mucosa by decreasing the serum IgA1 level; this led to clinical improvement in all patients.

Niaudet and Habib [28] conducted a prospective study of the treatment of severe forms of childhood HSPN and evaluated the effects of MPT therapy alone on the outcome and pathology of nephropathy. They reported that 11 of 38 children (21\%) still exhibited nephropathy, 4 had persistent nephropathy, and 4 progressed to end-stage renal failure. Moreover, a repeat biopsy within an interval of 7-24 months showed deterioration in the CI, despite an improvement in the AI in both the clinical recovery group and the group with minimal urinary abnormalities. In contrast, in our study, all but 1 patient showed negative proteinuria within 43 months of observation without any deterioration in renal function. Moreover, in addition to the decrease in AI, CI remained unchanged at the mean follow-up time of 20.8 \pm 5.5 months. The HSPN patients in the study by Niaudet and Habib [28] had higher disease severity than did the patients in our study, and the treatment protocol was different with regard to the number of MPT treatments and the therapy period. Although we cannot compare the 2 studies easily, our results suggest that the addition of tonsillectomy to MPT contributed beneficial effects.

Furthermore, the importance and efficacy of a prompt treatment initiation for achieving complete remission in patients with severe proteinuric HSPN has been demonstrated by several authors. Tanaka et al. [32] treated 9 patients with nephrotic-range HSPN with prednisolone and cyclophosphamide no later than 4 weeks after the onset of HSPN, and 7 of these patients achieved complete remission. In addition, plasmapheresis has been reported to significantly improve the renal outcome of severe pediatric HSPN if it is performed within 4 weeks of the onset of HSPN [35, 38]. When the start of plasmapheresis was delayed to $>8$ weeks after the onset of HSPN, the patients inevitably developed end-stage renal failure $[35,39]$. All of these reports suggest that early suppression of disease activity by immunosuppressants or elimination of circulating immune complexes is essential for attaining clinical remission of HSPN. However, even after such aggressive and prompt therapeutic approaches, a subset of HSPN patients does not respond well and may progress to end-stage renal failure through successive flare-ups. Indeed, in our study, 1 patient (No. 8) still had low-grade proteinuria even after additional treatments with MPT and immunosuppressants. However, all patients began treatment soon after the renal biopsy and promptly experienced a reduction in proteinuria and hematuria (8 patients achieved complete remission). Accordingly, early diagnosis based on renal biopsy and prompt initiation of immunosuppressive treatment may contribute to a favorable outcome $[25,31]$.

Because it was thought that the patients with ISKDC grade IV (Nos. 7 and 8) had a poor prognosis, aggressive treatment was required. Many studies have considered the prognostic significance of glomerular crescents in renal biopsies, and most reports agree that the presence of $>50 \%$ crescents at onset indicates a poor prognosis $[4,8,19,28]$. Therefore, we used an intravenous cyclophosphamide therapy regimen as an additional treatment. Cyclophosphamide is a powerful immunosuppressive drug, and its efficacy through oral administration in pediatric HSPN cases has been reported [30]. For adult cases, intravenous cyclophosphamide therapy (1,000 mg/m $\mathrm{m}^{2}$ once a month for 6 months) has been reported to be effective [40]. However, this therapy is very strong, so we may have overestimated the efficacy of MPT combined with tonsillectomy.

In conclusion, our study was the first prospective study of children with heavy proteinuric HSPN receiving early treatment of MPT combined with tonsillectomy, regardless of the episode of macrohematuria at tonsillitis and severity of histopathological findings. Our results were excellent compared with those of previous studies and suggest that MPT combined with tonsillectomy is effective for heavy proteinuric HSPN in children and may ame- 
liorate its histopathological progression and improve the clinical outcome. However, because the severity of proteinuria is the main risk factor for the progression of glomerular disease [41], additional observations, particularly long-term studies, are necessary to evaluate longterm efficacy. To date, no information is available on the clinical efficacy of tonsillectomy on the long-term renal survival of patients with HSPN compared with patients with IgA nephropathy $[12,13]$. In addition, there are some limitations to this study - namely, the small number of patients and the lack of a control group. For more accurate information, further evaluation will be required to validate our results. Despite these limitations, the present study suggests that early treatment with MPT combined with tonsillectomy is beneficial for children with a clinically severe form of HSPN.

\section{Acknowledgments}

The authors thank the members of the Department of Otorhinolaryngology at the Yamanashi University of Medicine for conducting the tonsillectomies and the members of the Department of Pathology for their valuable advice and comments in relation to this study.

\section{Disclosure Statement}

There are no conflicts of interest.

\section{References}

1 Counahan R, Winterborn MH, White RHR, Heaton JM, Meadow SR, Bluett NH, Swetchin H, Cameron JS, Chantler C: Prognosis of Henoch-Schönlein nephritis in children. Br Med J 1977;2:11-14.

2 Yoshikawa N, White RHR, Cameron AH: Prognostic significance of the glomerular changes in Henoch-Schönlein nephritis. Clin Nephrol 1982;16:223-229.

3 Austin HA, Balow JE: Henoch-Schönlein nephritis: prognosis features and the challenge of therapy. Am J Kidney Dis 1983;2:512-520.

4 Goldstein AR, White RHR, Akuse R, Chantler C: Long-term follow-up of childhood Henoch-Schönlein nephritis. Lancet 1992;339:280-282.

5 Ronkainen J, Nuutinen M, Koskimies O: The adult kidney 24 years after childhood Henoch-Schönlein purpura. A prospective cohort study. Lancet 2002;360:666-670.

6 Shenoy M, Bradbury MG, Lewis MA, Webb NJ: Outcome of Henoch-Schönlein purpura nephritis treated with long-term immunosuppression. Pediatr Nephrol 2007;22:1717-1722.

7 Ronkainen J, Ala-Houhala M, Huttunen NP, Jahnukainen T, Koskimies O, Ormala T, Nuutinen M: Outcome of Henoch-Schoenlein nephritis with nephrotic-range proteinuria. Clin Nephrol 2003;60: $80-84$.

8 Waldo FB: Is Henoch-Schönlein purpura the systemic form of IgA nephropathy? Am J Kidney Dis 1988;12:373-377.

9 Rai A, Nast C, Adler S: Henoch-Schönlein purpura nephritis. J Am Soc Nephrol 1999;10:2637-2644.

10 Davin JC, Ten Berge IJ, Weening JJ: What is the difference between IgA nephropathy and HenochSchönlein purpura nephritis? Kidney Int 2001;59:823-834.

11 Evans DJ, Williams DG, Peters DK, Sissons JG, Boulton-Jones JM, Ogg CS, Cameron JS, Hoffbrand BI: Glomerular deposition of properdin in Henoch-Schönlein syndrome and idiopathic focal nephritis. Br Med J 1973;3:326-328.

12 Hotta O, Miyazaki M, Furuta T, Tomioka S, Chiba S, Horigome I, Abe K, Taguma Y: Tonsillectomy and steroid pulse therapy significantly impact on clinical remission in patients with IgA nephropathy. Am J Kidney Dis 2001;38:736-743. 
13 Xie Y, Nishi S, Ueno M, Imai N, Sakatsume M, Narita I, Suzuki Y, Akazawa K, Shimada H, Arakawa $\mathrm{M}$, Gejyo F: The efficacy of tonsillectomy on long-term renal survival in patients with IgA nephropathy. Kidney Int 2003;63:1861-1867.

14 Kawasaki Y, Tanaka K, Suyama K, Isome M, Suzuki H, Sakuma H, Fujiki T, Suzuki H, Hosoya M: Efficacy of tonsillectomy pulse therapy versus multiple-drug therapy for IgA nephropathy. Pediatr Nephrol 2006;21:1701-1706.

15 Sugiyama H, Watanabe N, Onoda T, Kikumoto Y, Yamamoto M, Maeta M, Ohara N, Maeshima Y, Yamasaki Y, Makino H: Successful treatment of progressive Henoch-Schönlein purpura nephritis with tonsillectomy and steroid pulse therapy. Intern Med 2005;44:611-615.

16 Inoue CN, Chiba Y, Morimoto T, Nishio T, Kondo Y, Adachi M, Matsutani S: Tonsillectomy in the treatment of pediatric Henoch-Schönlein nephritis. Clin Nephrol 2007;67:298-305.

17 Kawasaki Y, Suyama K, Matsumoto A, Takano K, Hashimoto K, Suzuki S, Suzuki J, Suzuki H, Hosoya M: Efficacy of tonsillectomy plus methylprednisolone pulse therapy for a child with HenochSchoenlein purpura nephritis. Tohoku J Exp Med 2007;211:291-295.

18 Mori Y, Hiraoka M, Suganuma N, Tsukahara H, Yoshida H, Mayumi M: Urinary creatinine excretion and protein/creatinine ratios vary by body size and gender in children. Pediatr Nephrol 2006; 21:683-687.

19 Houser M: Assessment of proteinuria using random urine samples. J Pediatr 1984;104:845-848.

20 National High Blood Pressure Education Program Working Group on High Blood Pressure in Children and Adolescents: The fourth report on the diagnosis, evaluation, and treatment of high blood pressure in children and adolescents. Pediatrics 2004;114:555-576.

21 Meadow SR, Glasgow EF, White RHR, Moncrieff MW, Cameron JS, Ogg CS: Schonlein-Henoch nephritis. QJ Med 1972;41:241-258.

22 Sönmez F, Mir S, Cura A, Cakir D, Başdemir G: Clinicopathologic correlations of Henoch-Schönlein nephritis in Turkish children. Pediatr Int 1999;41:353-356.

23 Schwartz GJ, Haycock GB, Edelmann CM Jr, Spitzer A: A simple estimate of glomerular filtration rate in children derived from body length and plasma creatinine. Pediatrics 1976;58:259-263.

24 Andreoli SP, Bergstein JM: Treatment of severe IgA nephropathy in children. Pediatr Nephrol 1989; 3:248-253.

25 Foster BJ, Bernard C, Drummond KN, Sharma AK: Effective therapy for severe Henoch-Schönlein purpura nephritis with prednisone and azathioprine: a clinical and histopathologic study. J Pediatr 2000;136:370-375.

26 Mir S, Yavascan O, Mutlubas F, Yeniay B, Sonmez F: Clinical outcome in children with HenochSchönlein nephritis. Pediatr Nephrol 2007;22:64-70.

27 Ninchoji T, Kaito H, Nozu K, Hashimura Y, Kanda K, Kamioka I, Shima Y, Hamahira K, Nakanishi K, Tanaka R, Yoshikawa N, Iijima K, Matsuo M: Treatment strategies for Henoch-Schönlein purpura nephritis by histological and clinical severity. Pediatr Nephrol 2011;26:563-569.

28 Niaudet P, Habib R: Methylprednisolone pulse therapy in treatment of severe forms of SchönleinHenoch purpura nephritis. Pediatr Nephrol 1998;12:238-243.

29 Kawasaki Y, Suzuki J, Nozawa R, Suzuki S, Suzuki H: Efficacy of methylprednisolone and urokinase pulse therapy for severe Henoch-Schönlein nephritis. Pediatrics 2003;111:785-789.

30 Tarshish P, Bernstein J, Edelmann CM Jr: Henoch-Schönlein purpura nephritis: course of disease and efficacy of cyclophosphamide. Pediatr Nephrol 2004;19:51-56.

31 Iijima K, Ito-Kariya S, Nakamura H, Yoshikawa N: Multiple combined therapy for severe HenochSchönlein nephritis in children. Pediatr Nephrol 1998;12:244-248.

32 Tanaka H, Suzuki K, Nakahata T, Ito E, Waga S: Early treatment with oral immunosuppressants in severe proteinuric purpura nephritis. Pediatr Nephrol 2003;18:347-350.

33 Shin JI, Park JM, Shin YH, Kim JH, Kim PK, Lee JS, Jeong HJ: Cyclosporin A therapy for severe Henoch-Schönlein nephritis with nephritic syndrome. Pediatr Nephrol 2005;20:1093-1097.

34 Shin JI, Park JM, Shin YH, Kim JH, Lee JS, Kim PK, Jeong HJ: Can azathioprine and steroids alter the progression of severe Henoch-Schönlein nephritis in children? Pediatr Nephrol 2005;20:10871092.

35 Hattori M, Ito K, Konomoto T, Kawaguchi H, Yoshioka T, Khono M: Plasmapheresis as the solo therapy for rapidly progressive Henoch-Schoenlein purpura nephritis in children. Am J Kidney Dis 1999; 33:427-433. 
36 Inoue CN, Nagasaka T, Matsutani S, Ishidoya M, Homma R, Chiba Y: Efficacy of early dental and ENT therapy in preventing nephropathy in pediatric Henoch-Schönlein purpura. Clin Rheumatol 2008;27:1489-1496.

37 Kawaguchi T, Ieiri N, Yamazaki S, Hayashino Y, Gillespie B, Miyazaki M, Taguma Y, Fukuhara S, Hotta O: Clinical effectiveness of steroid pulse therapy combined with tonsillectomy in patients with immunoglobulin A nephropathy presenting glomerular haematuria and minimal proteinuria. Nephrology 2010;15:116-123.

38 Gianviti A, Trompeter RS, Barrant TM, Lythgoe MF, Dillon MJ: Retrospective study of plasma exchange in patients with idiopathic rapidly progressive glomerulonephritis and vasculitis. Arch Dis Child 1996;75:186-190.

39 Schärer K, Krmar R, Querfeld U, Ruder H, Waldherr R, Schaefer F: Clinical outcome of SchönleinHenoch purpura nephritis in children. Pediatr Nephrol 1999;13:816-823.

40 López Meiller MJ, Cavallasca JA, Maliandi Mdel R, Nassweter GG: Henoch-Schonlein purpura in adults. Clinics (São Paulo) 2008;63:273-276.

41 D’Amico G: Tubulointerstitium as predictor of progression of glomerular disease. Nephron 1999;83: 289-295. 